\title{
Rational Prediction Of Future Pension Expense: A Simulation Approach
}

\author{
Alan I. Blankley, (Email: aiblankl@email.unc.edu), University of North Carolina Charlotte
}

Philip G. Cottell Jr., (Email: cottelpg@muohio.edu), Miami University, Ohio

Richard H. McClure, (Email: mcclurrh@muohio.edu), Miami University, Ohio

\begin{abstract}
Because future pension expense can have a material influence on a firm's future earnings, financial analysts are faced with the difficult task of forecasting its impact. The purpose of this paper is to demonstrate a model that can be used with a simulation approach to predict future pension expense and its associated uncertainties. Because of the importance and complexity of the pension expense component in the estimate of future earnings, a simulation model acts as a powerful analytical tool that can give the analyst greater confidence as to the magnitude and variability of future pension expense.
\end{abstract}

\section{Introduction}

$\mathrm{n}$ the course of their analysis of financial statements, many financial analysts focus on reported earnings in order to understand equity pricing. Accurate prediction of future earnings requires an accurate prediction of the revenues and expenses that will have an impact on future earnings. In order to develop a reasonably accurate estimate of future costs, analysts will often have to estimate future pension costs. Pension cost, however, is notoriously difficult to predict, and yet may have a material impact on the firm's future earnings.

Indeed, for the past several months, the popular financial press has speculated on the repercussions of current market conditions on the reported annual pension cost. Readers of the popular "Heard on the Street" column were warned that pension costs threatened earnings (Brown and Weil, 2001). In the same space Bulkeley (2002) warned that IBM's earnings were at risk because of pension costs. Writing in Money Magazine Frederick (2002) cited manipulation of pension expense as a way managers could "goose" earnings. Carlson (2002) asserts that companies use pension accounting to "trick" investors. Nonetheless, the popular press is not in complete agreement about the gloom surrounding pensions. Schultz and Squeo (2002) make the case that concerns over negative pension plan effects have been exaggerated.

How should the analyst react to the increased rhetoric about pensions? This paper proposes a rational approach that may be used to predict the future earnings effects attributable to a firm's defined benefit pension plan.

\subsection{Peculiarities of Annual Pension Cost}

Despite the popularity enjoyed by defined contribution plans over the past two decades, they represent only twenty percent of total household pension reserves (Newell, Kreuz, and Hurtt (2002). Thus, defined benefit plans continue to be a significant consideration in corporate financial reporting. For those firms that have defined benefit plans, annual pension cost is a material item in the calculation of earnings.

Barth and Murphy (1994) found that forty-three percent of all disclosed financial information is contained in six line items, one of which is annual pension cost. Moreover Statement of Financial Accounting Standards No. 87 and Statement of Financial Accounting Standards No .132 require extensive disclosure about defined benefit plans in financial statement footnotes. Thus, financial analysts have a great deal of information to work with when dealing with annual pension cost. 
Despite the availability of information with which to work, prediction of annual pension cost is a daunting task in times of uncertainty. This is the case because calculating annual pension cost is a complex task even in periods of relative certainty. Pension cost is comprised of up to six separate components, of which the three most influential components are the service cost, the interest cost, and the expected return on plan assets. Each of these three components is heavily influenced by certain rate estimates, which incorporate both historical and future information, as well as exogenous and endogenous information. Two rate estimates that have the greatest impact are the discount rate and the long-term return on plan assets.

The discount rate affects pension cost in two ways. First, it is the rate used to discount the firm's future annual service cost annuity to the present. Second, it is the rate used to discount the firm's pension liability to the present, which then becomes the basis for the interest cost component of pension expense, calculated as the pension liability (the Projected Benefit Obligation) multiplied times the discount rate. Ultimately, the effect the discount rate has on reported pension expense is pervasive and material. Any decrease in the discount rate can increase pension cost dramatically.

The expected rate of return, which is unrelated to the discount rate, has the opposite effect on pension cost. It is supposed to reflect both the firm's historical returns as well as the firm's future expectations of investment performance, and it is multiplied by the market-related asset value to arrive at an estimate of the firm's future investment returns. This estimate is then used to reduce pension cost. Over the past decade, many firms have enjoyed very high returns on pension plan assets, and as a result have not needed to fund their plans. In response many of these firms have raised their expected rate of return on plan assets. Empirically, over the last seven years, the mean expected return on plan assets has been between seven and nine percent. In some cases the resulting expected return on plan assets has been so high that companies have reported pension income rather than expense ${ }^{1}$.

What makes estimating pension expense so difficult, especially in periods of economic uncertainty, is that firms have wide latitude as to the rate estimates they use. As we mentioned above, the estimates can materially affect the reported expense, but since management controls the rate assumptions, it is difficult for an analyst to do more than to estimate the direction of rate changes; the magnitude of the rate change, and hence, the ultimate effect on pension expense is much more uncertain. In many cases, analysts do not have sufficient information to narrow the uncertainty associated with the changes that will be made with these rates. Thus, with interest rates falling and with decreased expectations about portfolio returns, a rational approach to modeling pension rate changes will greatly assist financial analysts in predicting pension cost. This approach allows comparability among similarly situated firms, mitigating the potential impact of disparate discount rates. In this paper we develop a model analysts may use to predict annual pension expense. We then propose simulation as an approach that can give analysts the ability to quantify the uncertainty encompassing their prediction of annual pension expense.

\subsection{Analytical Model of Pension Expense}

We gathered data from Compustat on all firms that disclosed certain defined benefit pension plan variables. This resulted in a sample of 1,116 firms. From the sample we constructed three hypothetical firms using data from real firms in the sample. A hypothetical Large Company was constructed using data at the upper $75^{\text {th }}$ percentile point for the each of the following variables: projected benefit obligation, service cost, fair value of plan assets, unrecognized gain or loss, unamortized prior service cost, benefits paid, and company contributions to the plan. A hypothetical Mid-sized Company was constructed in a similar manner using data at the median point for the same variables. Finally a hypothetical Small Company was constructed using data for the same variables at the lower $25^{\text {th }}$ percentile point. We constructed these hypothetical companies for our simulation because we did not want the idiosyncrasies of any particular firm to enter into the analysis. All variable values were taken from Compustat except benefits and contributions, which are not available on Compustat. We collected these items from each firm's 10K filing.

\footnotetext{
${ }^{1}$ Our sample indicates that in 2000, 403 out of 1116 firms in the sample (34.8\%) reported a net pension credit.
} 
In order to forecast annual pension expense, we began with the following simple representation:

$\mathrm{PEXP}=\mathrm{SC}+\mathrm{IC}-\mathrm{ER}+\mathrm{AMORTPSC}+\mathrm{AMORTGL}$

Where,

$\mathrm{PEXP} \quad=$ Pension expense

SC $\quad=$ Service Cost

IC $\quad=$ Interest Cost

ER $\quad=$ Expected return on plan assets

AMORTPSC = Amortization of prior service costs, which can be either a positive or negative value

AMORTGL = Amortization of unrecognized gains and losses subject to the corridor approach, which can be either a positive or negative value

We then developed an analytical model based on the simple accounting identities as defined above. The expanded model is expressed as follows:

$\operatorname{PEXP}(i)=\left[\frac{\sum_{j=1}^{T A} \frac{A S C A_{j}}{(1+D R(i))^{j}}}{(1+D R(i))^{T B R-1}}\right]+D R(i) *\left[\frac{\sum_{j=1}^{T A} \frac{F V R A_{j}}{(1+D R(i))^{j}}}{(1+D R(i))^{T B R}}\right]-[E R R(i)] *\left[\frac{\sum_{j=-4}^{0} F V P A_{j}}{5}\right]+\frac{\operatorname{UnPSC}(i)}{A S L} \pm A M O R T G L(i)$

Where,

$\operatorname{PEXP}(\mathrm{i}) \quad=$ Pension expense at period $\mathrm{i}$

$\operatorname{DR}(\mathrm{i}) \quad=$ Discount Rate at period $\mathrm{i}$

ASCAj $\quad=$ Annual Firm-wide Service Cost at time $\mathrm{j}$ (assumed constant)

TA $\quad=$ term of the annuity payments, assumed to be 20 years

TBR $\quad=$ Time remaining before retirement in years, assumed to be 20 years

FVRAj $=$ Firm-wide value of the retirement annuity at time $\mathrm{j}$ (assumed constant)

ERR(i) $\quad=$ Expected rate of return at period $\mathrm{i}$

FVPAj $\quad=$ Fair value of pension plan assets at time $\mathrm{j}$

UnPSC(i) = Unrecognized Prior Service Cost at period $\mathrm{i}$

ASL $\quad=$ Average service life of employees remaining, assumed to be 20 years

AMORTGL(i) = Amortization of Unrecognized Gains (-) or Losses (+) for period i

The first term in the model represents the annual service cost. Service cost is the present value of benefits earned by employees during the current period based on future salary levels, and represents an annuity stream to the sponsoring firm to be paid over the retirement period of employees. The two necessary starting values for service cost calculation are the discount rate and ASCA(j), which represents the annual firm-wide service cost annuity benefit. To obtain the discount rate, we simply took the mean discount rate (7.5\%) from our sample.

To obtain the firm-wide service cost, however, we could not use the corresponding descriptive statistic from the sample. Using the median service cost, for example, would allow us to calculate pension expense for the median firm in year 0 (the base year), but it would not allow us to capture the influence the discount rate has on service cost when it (the discount rate) changes. In other words, by using median service costs, we could project service costs into the future using some predictive technique, but these projections would be insensitive to future discount rate changes. To counter this problem, the service cost in period 0 was derived equal to the median service cost for our sample. Assuming ASCA to be constant we applied a discount rate of $7.5 \%$, then derived the value of ASCA based upon the following rearrangement: 


$$
A S C A=\frac{S C(0)(1+D R(0))^{T B R-1}}{T A \sum_{j=1}^{T A} \frac{1}{(1+D R(0))^{j}}}
$$

where $\mathrm{SC}(0)$ and $\mathrm{DR}(0)$ are the service cost and discount rates respectively in period 0 for the median firm.

Thus, we were able to derive the amount of the annuity benefit, which, when discounted first over the stream of future payments starting at the retirement date, then from the retirement date to the present as a single sum, gave us the median service cost from our sample. We applied this procedure for the $25^{\text {th }}$ and $75^{\text {th }}$ percentile firms as well.

The second term represents the interest cost component of pension expense. It is calculated as the discount rate times the Projected Benefit Obligation (PBO). Since PBO is sensitive to changes in the discount rate, we applied a similar procedure to the one used to obtain service cost. In this case we derived FVRA (the firm-wide value of the retirement annuity), assumed to remain constant over the term of the annuity payments, from the following equation by using a discount rate of $7.5 \%$, and setting PBO for period zero equal to the $25^{\text {th }}$ percentile PBO, the median PBO, and the $75^{\text {th }}$ percentile PBO from our sample, respectively, then solving for FVRA using the following rearrangement.

FVRA $=\left[\frac{P B O(0)\{1+D R(0)\}^{T B R}}{T A \sum_{j=1}^{T A} \frac{1}{\{1+D R(0)\}^{j}}}\right]$

Once FVRA was known, we were able to find the value of PBO under different discount rate estimates. Then, after obtaining estimates of the $\mathrm{PBO}$, we obtain the interest cost component under the various rate assumptions by multiplying the term by different assumed discount rates. We vary the discount rate from $6 \%-8.5 \%$.

Interest Cost $(\mathrm{i})=[D R(i)] *\left[\frac{\sum_{j=1}^{T A} \frac{F V R A}{(1+D R(i))^{j}}}{(1+D R(i))^{T B R}}\right]$

The third term in the model is the expected return on plan assets, calculated as the expected rate of return times the market-related asset value, which we assumed was an average of the previous five year fair value of plan asset balances. ${ }^{2}$ The last two terms in the model represent the unrecognized prior service cost and the amortization of gains or losses components.

\section{A Simulation Model}

In order to estimate pension expense, we used the percentile data for the variables we collected as input to the analytical model we developed. Using this data and the model, we simulated the process that generates pension

\footnotetext{
${ }^{2}$ Under SFAS 87, the market-related asset value may be either the fair market value or an average of the fair market values for up to five years. We used the five year average to provide the most smoothing in the model.
} 
expense for two periods. In the simulation, the expected rate of return, the actual rate of return, and the discount rate for periods 1 and 2 are uncertain and are modeled as random variables with associated probability distributions. In performing the simulation, a value is generated randomly for each random variable from its associated probability distribution; these values are then used to calculate the output values for the simulation, i.e., pension expense in periods 1 and 2. The range of values that can be taken by each of the random variables is specified by the minimum and maximum values in Table 1 if the random variable for the experiment is assumed to follow the triangular distribution. For the experiment where a random variable is assumed to follow a custom distribution, the values that each random variable can take on are specified in Table 3. The negative values in Table 1 for Actual Rate of Return indicate that the rate of return on pension assets may be negative, a decrease in the value of the assets, e.g., the price of stocks.

This procedure is repeated a large number of times and the result is the representation of the effect of the uncertainty of the inputs on the output values. These outputs are usually represented as a relative frequency distribution that is used as an estimate of the probability distribution of the simulation output variable or variables. In our simulation, the values generated for the projected benefit obligation (PBO), the fair value of plan assets (PA), and the accumulated unrecognized gains and losses (AGL) at the end of the first period become the initial values for those three variables in the second period. Therefore the simulation is dynamic rather than static in that the values of the variables of interest are related over multiple time periods.

We conducted two simulation experiments using two different assumptions regarding the random variables. Under the first assumption, the analyst knows little about the distribution of the unknown random variables, but is able to predict a most likely value, a minimum value and a maximum value for each. Under the second assumption the analyst has in mind some probabilities to associate with each value of the discount rate and the expected return on plan assets.

\section{The Triangular Distribution}

For situations where little is known about the relative likelihood of values taken on by a variable that is to be modeled as a random variable, modelers often choose the triangular probability distribution to represent the distribution of the random variable. Although there are many theoretical probability distributions available to represent uncertainty in simulation models, the triangular distribution is the distribution of choice when little data is available for fitting a distribution for the variable. The triangular distribution is used as a rough approximation for the actual unknown distribution and requires only three generally straightforward parameter estimates to define the distribution. The required values are the smallest value the variable can take on, the largest value the variable can take on, and the most likely value the variable can take on. The triangular distribution is particularly valuable in estimating future pension expense because we don't know what will happen to the pension rates in the future, and it allows us to model the expense while maintaining uncertainty in the rates. Thus, in cases where the analyst is uncertain about the probability distribution of the discount rate, the expected rate of return, and the actual rate of return, the triangular distribution provides a useful way to model that uncertainty. For the purpose of our simulation, we chose the rates represented in the table below.

We ran the simulation with 10,000 iterations using the triangular distribution with the associated parameters in Table 1. Figure 1 contains a histogram of the pension expense values generated by the simulation for periods 1 and 2 for Large Company. Figure 2 shows a similar histogram for Mid-sized Company, and Figure 3 shows the histogram for Small Company. The corresponding numerical results are summarized in Table 2. The mean, median, standard deviation, minimum, and maximum values displayed in the table are calculated from the 10,000 values generated by the simulation for pension expense in periods 1 and 2 . These values are to be viewed as values obtained from a random sample. The straightforward statistical methods that are indicated below can thus be employed to estimate corresponding population parameter values. These methods were then used to construct the 95\% confidence interval for the corresponding population mean pension expense (or expected value of pension expense) for the two periods shown in the table. The width of the confidence interval suggests the uncertainty that is inherent in the estimation process. 
Table 1: Values Used for Triangular Distribution

\begin{tabular}{lccc|ccc}
\hline & \multicolumn{3}{c|}{ Period 1 } & \multicolumn{3}{c}{ Period 2 } \\
\hline & & & Most & & \multicolumn{2}{c}{ Most } \\
Rate & Min & Max & Likely & Min & Max & $6.5 \%$ \\
\hline Discount Rate & $6.0 \%$ & $7.5 \%$ & $7.0 \%$ & $5.5 \%$ & $7.0 \%$ & $7.0 \%$ \\
Expected Rate of Return & $5.0 \%$ & $9.0 \%$ & $8.0 \%$ & $5.0 \%$ & $8.0 \%$ & $-10 \%$ \\
Actual Rate of Return & $-15 \%$ & $5.0 \%$ & $-10 \%$ & $-15 \%$ & $5.0 \%$ & \\
\hline
\end{tabular}

Table 2 also displays interval estimates for individual values of pension expense. These intervals were constructed, using the Empirical Rule, by adding and subtracting one standard deviation to the sample mean for the $68 \%$ interval and adding and subtracting two standard deviations to the sample mean for the $95 \%$ interval. The intervals centered on the sample mean suggest that $68 \%$ and $95 \%$ of the pension expense values will fall within these intervals respectively. For our purposes, it can be interpreted by an analyst to mean that with probability 0.68 and 0.95 that the pension expense will fall within the respective intervals for the assumptions used for the pension expense prediction. The only assumption associated with the use of the empirical rule is that the frequency distribution for the associated variable is approximately symmetric and unimodal, which is verified by examining figures 1 through 3. For the large company, for example, the analyst can conclude that the pension expense in period one will fall between $\$ 13$ million and $\$ 22.6$ million with a probability of approximately 0.68 . Similarly the analyst can conclude that period one pension expense will fall between $\$ 8.5$ million and $\$ 26.5$ with a probability of approximately 0.95 . The table shows corresponding values for the other two companies and for the second period.

Table 2: Estimation of Pension Expense Using Triangular Distribution

\begin{tabular}{lll}
\hline Large Company (75\%) & Period 1 & Period 2 \\
\hline Mean & $\$ 17,506,159$ & $\$ 27,296,792$ \\
Median & $\$ 17,162,823$ & $\$ 27,142,910$ \\
Standard Deviation & $\$ 4,517,356$ & $\$ 4,699,245$ \\
Minimum & $\$ 6,135,299$ & $\$ 13,880,225$ \\
Maximum & $\$ 33,348,527$ & $\$ 44,702,680$ \\
95\% Confidence Interval & $\$ 17,417,619-\$ 17,594,699$ & $\$ 27,205,275-\$ 27,388,309$ \\
68\% Emp. Rule Estimate & $\$ 12,988,803-\$ 22,627,547$ & $\$ 22,627,547-\$ 31,966,037$ \\
95\% Emp. Rule Estimate & $\$ 8,471,447-\$ 26,540,871$ & $\$ 17,958,302-\$ 36,635,282$ \\
\hline & & \\
Mid-sized Company (50\%) & Period 1 & Period 2 \\
\hline Mean & $\$ 5,404,646$ & $\$ 7,932,338$ \\
Median & $\$ 5,334,894$ & $\$ 7,984,082$ \\
Standard Deviation & $\$ 1,057,009$ & $\$ 1,098,520$ \\
Minimum & $\$ 2,719,008$ & $\$ 4,313,550$ \\
Maximum & $\$ 9,119,371$ & $\$ 11,961,655$ \\
95\% Confidence Interval & $\$ 5,383,929-\$ 5,425,363$ & $\$ 7,910,807-\$ 7,953,869$ \\
68\% Emp. Rule Estimate & $\$ 4,347,637-\$ 6,461,655$ & $\$ 6,833,818-\$ 9,030,858$ \\
95\% Emp. Rule Estimate & $\$ 3,290,628-\$ 7,518,664$ & $\$ 5,735,298-\$ 10,129,378$ \\
\hline & & \\
Small Company (25\%) & Period 1 & Period 2 \\
\hline Mean & $\$ 1,479,656$ & $\$ 2,185,707$ \\
Median & $\$ 1,463,812$ & $\$ 2,176,114$ \\
Standard Deviation & $\$ 256,542$ & $\$ 276,624$ \\
Minimum & $\$ 850,946$ & $\$ 1,286,128$ \\
Maximum & $\$ 2,371,307$ & $\$ 3,198,330$ \\
95\% Confidence Interval & $\$ 1,474,628-\$ 1,484,684$ & $\$ 2,180,285-\$ 2,191,129$ \\
68\% Emp. Rule Estimate & $\$ 1,223,114-\$ 1,736,198$ & $\$ 1,632,459-\$ 2,738,955$ \\
95\% Emp. Rule Estimate & $\$ 966,572-\$ 1,992,740$ & \\
\hline
\end{tabular}


Figure 1: Pension Expense Simulation for Large Company Triangular Distribution
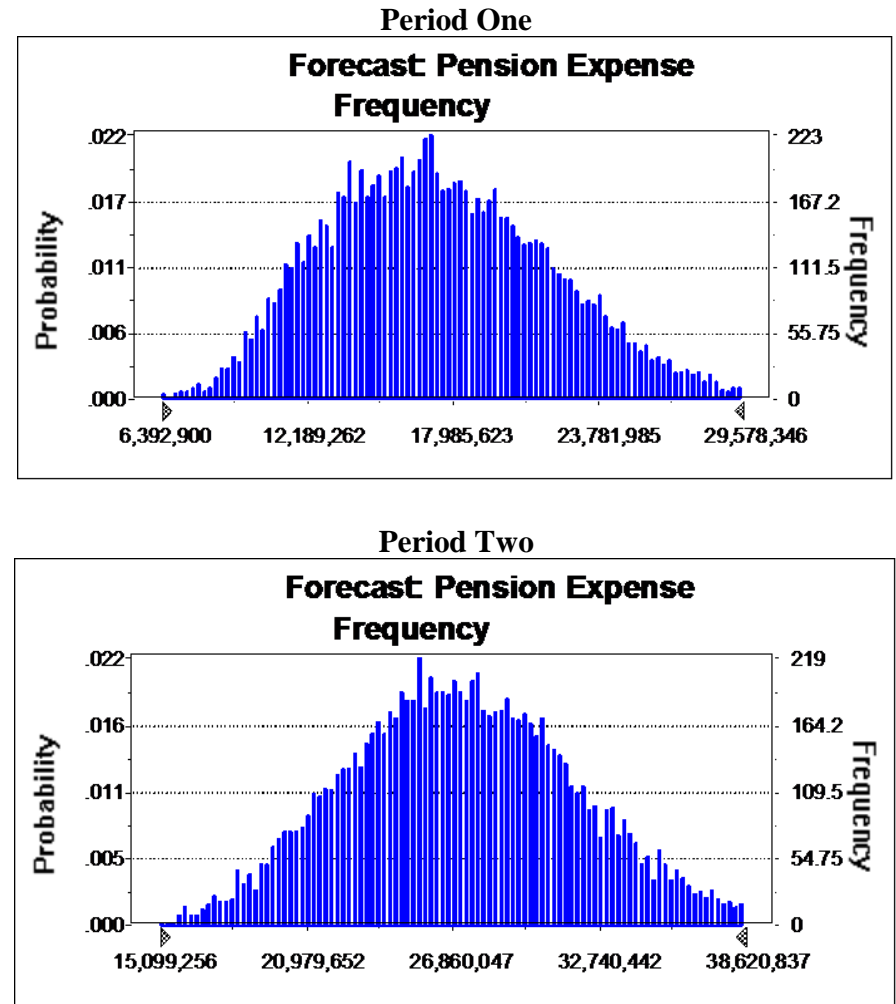

Figure 2: Pension Expense Simulation for Mid-sized Company Triangular Distribution

Period One

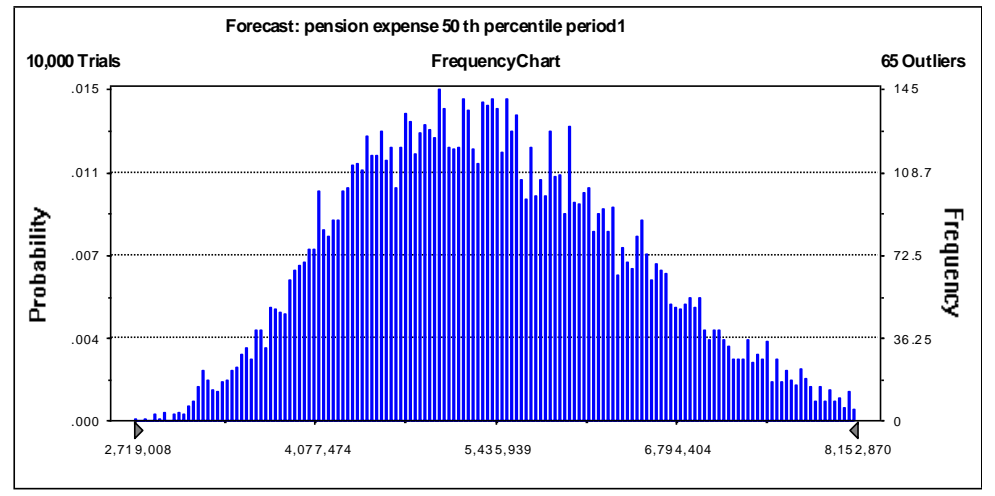


Period Two

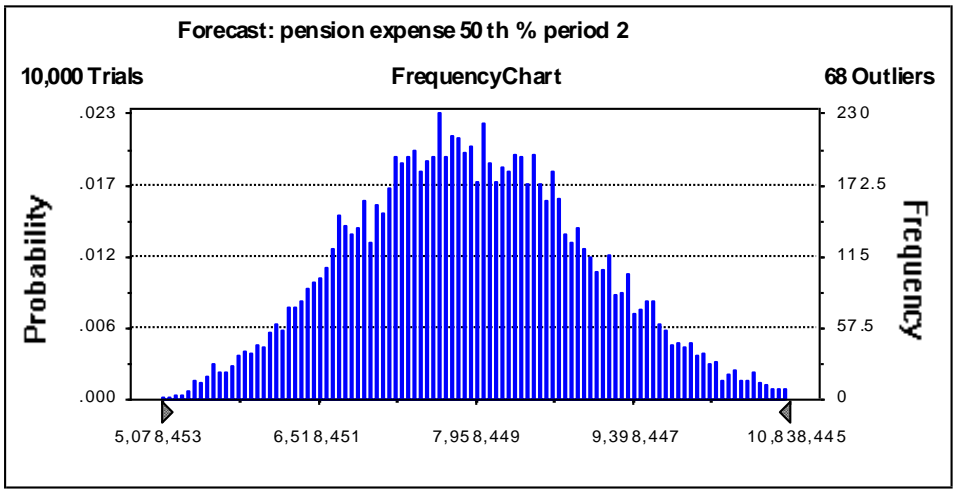

Figure 3: Pension Expense Simulation for Small Company Triangular Distribution

Period One

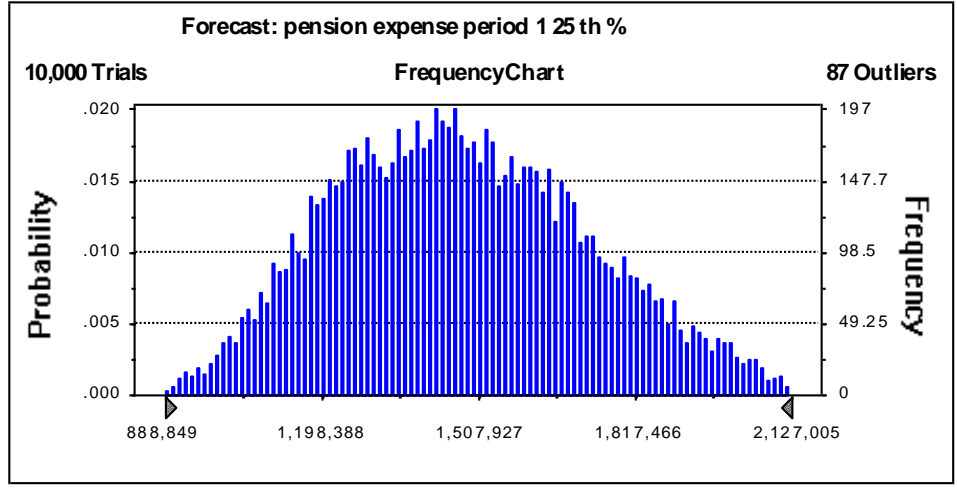

Period 2

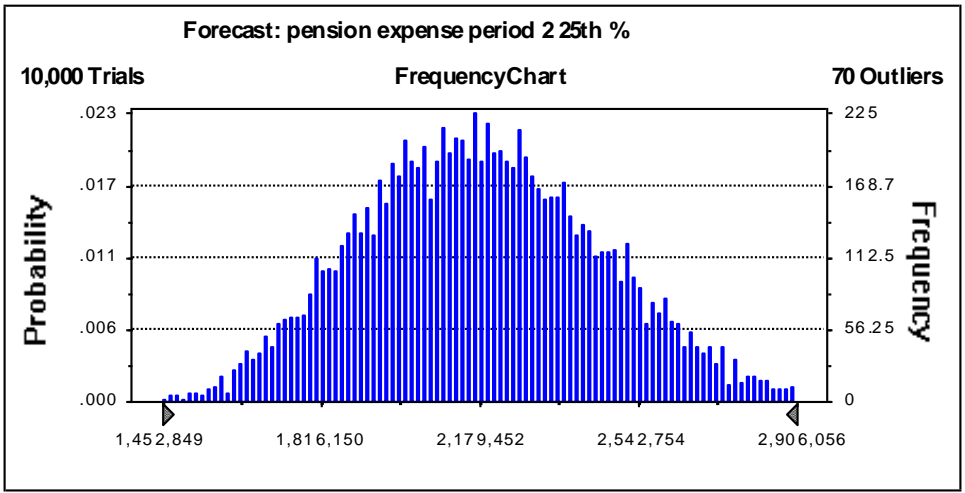

\section{The Custom Distribution}

It may be that in particular cases, the analyst believes that he or she can assign probabilities to the possible values of the unknown random variables. This may be particularly appropriate for two of the variables in this study - the discount rate and the expected return on plan assets - because management chooses the values for these two variables. Management is unlikely to choose rates that fall between quarter point intervals. Thus it might be 
better to represent these variables as discrete random variables rather than continuous random variables. A discrete random variable is one that is assumed to take on only particular, specified values. The associated probability distribution is defined by specifying the particular values the variable can take on and their associated probability values. In Table 3, we specified what we believed to be reasonable values for each of the variables along with their associated probabilities. The actual rate of return was left as a continuous variable since it may take on any value. We used the same minimum, most likely, and maximum values as the parameters for the triangular distribution for actual return on plan assets as we had in the previous simulations.

Table 3: Values chosen for the Custom Distribution

\begin{tabular}{ccc}
\hline \multicolumn{3}{c}{ Expected Rate of Return } \\
Rate & Period 1 Probability & \begin{tabular}{c} 
Period 2 Probability \\
\hline $9.0 \%$
\end{tabular} \\
$8.5 \%$ & 0.05 & 0.02 \\
$8.0 \%$ & 0.20 & 0.16 \\
$7.5 \%$ & 0.50 & 0.25 \\
$6.0 \%$ & 0.20 & 0.55 \\
\multicolumn{3}{c}{ Discount Rate } \\
Rate & 0.05 & 0.02 \\
\hline $7.5 \%$ & Period 1 Probability & Period 2 Probability \\
$7.0 \%$ & 0.05 & 0.05 \\
$6.5 \%$ & 0.60 & 0.30 \\
$6.0 \%$ & 0.20 & 0.45 \\
$5.5 \%$ & 0.10 & 0.15 \\
\hline
\end{tabular}

We again ran the simulation with 10,000 iterations using the specified distribution for each of the hypothetical companies. Figure Four contains a histogram of the results for Large Company. Figure Five shows a similar histogram for Mid-sized Company, and Figure Six shows the histogram for Small Company. Our numerical results are summarized in Table 4. For all three companies, the table shows the measures of central tendency for pension expense - the mean, the median and the $95 \%$ confidence interval for the population mean along with appropriate interval estimates for individual values of pension expense - that were generated by the simulation model

under the custom distribution. Because the pension expense distribution is discrete in period 1, the empirical rule cannot be used to construct interval estimates for individual values of pension expense in period 1. In this situation, the Chebyshev Rule can supply some information, although not as good as that provided by the Empirical Rule. Chebyshev's Rule states that at least $75 \%$ of the values in the sample will fall within two standard deviations of the mean and at least $89 \%$ of the values will fall within three standard deviations of the mean. These values are shown for pension expense in period 1 in Table 4 . The values suggest that an analyst could conclude that the pension expense in period 1 would fall within the specified intervals with probabilities that are at least as large as 0.75 and 0.89 respectively. The intervals estimates for pension expense for period 2 are determined by the empirical rule as was discussed for the previous simulation.

Notice that in period two, the values generated by the simulation take on the characteristics of a continuous variable. This occurs because the effects of a change in actual return on plan assets do not affect the model's results until the second period. With this distribution we may therefore use the empirical rule to define interval estimates for pension expense. 
Figure 4: Pension Expense Simulation for Large Company Custom Distribution

Period One

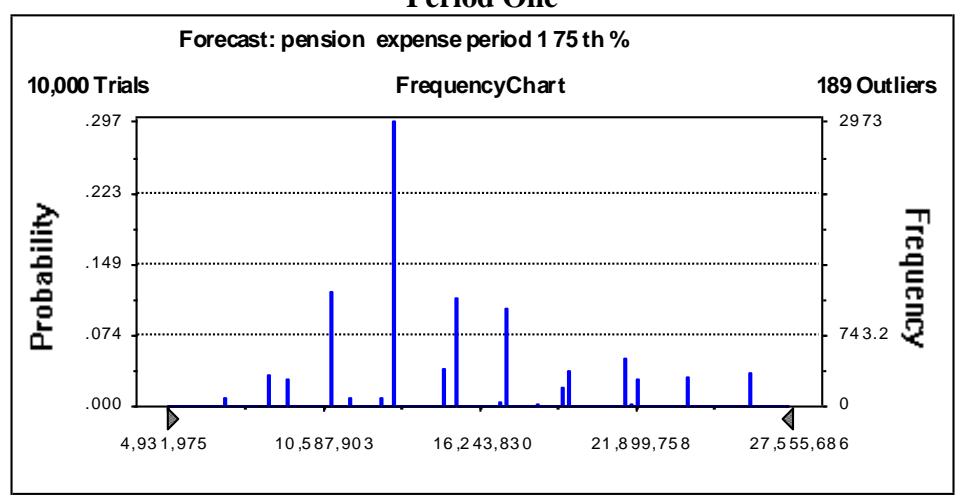

Period Two

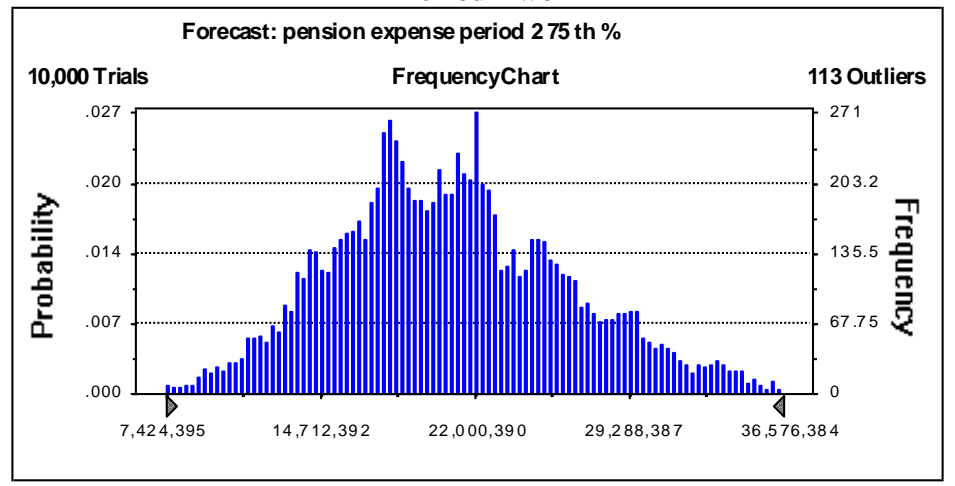

Figure 5: Pension Expense Simulation for Mid-sized Company Custom Distribution

Period One

\begin{tabular}{|c|c|c|c|c|}
\hline \multicolumn{5}{|c|}{ Forecast: pension expense period 150 th percentil } \\
FrequencyChart
\end{tabular}


Period Two

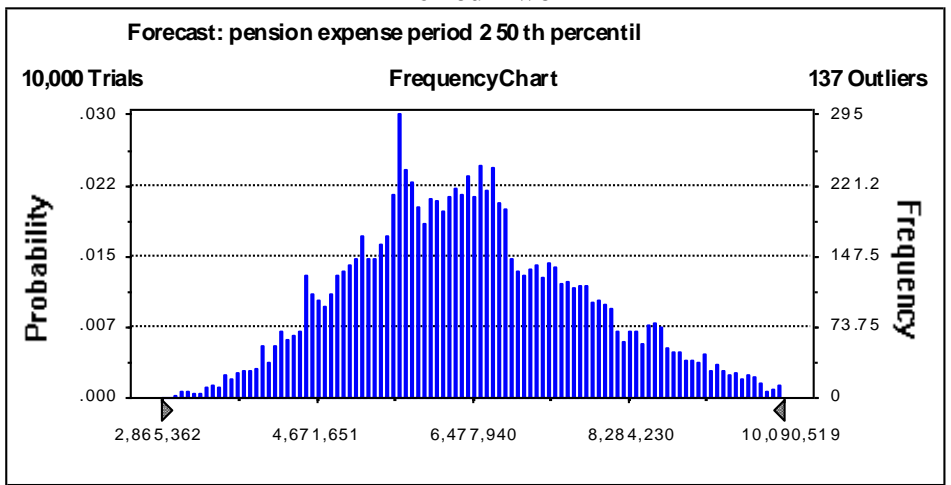

Figure 6: Pension Expense Simulation for Small Company Custom Distribution

Period One

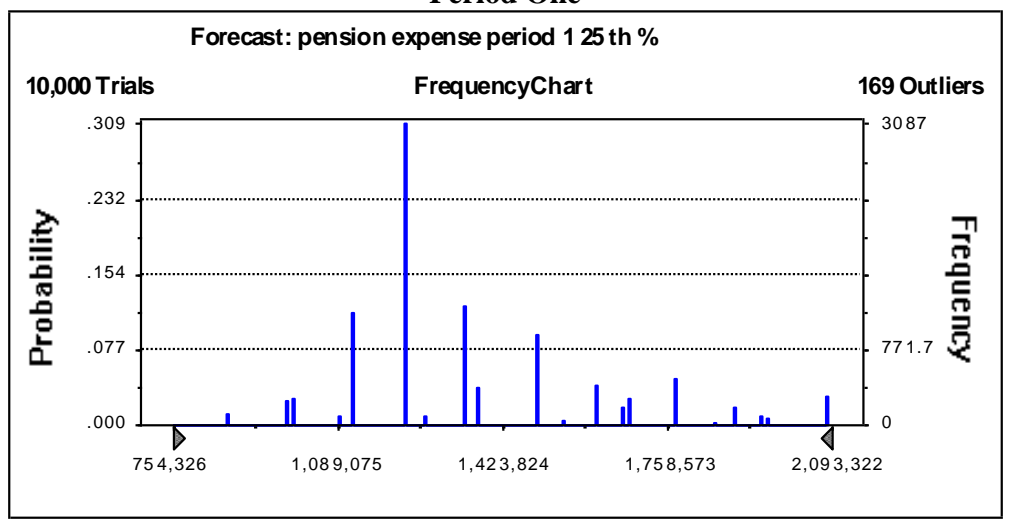

Period Two

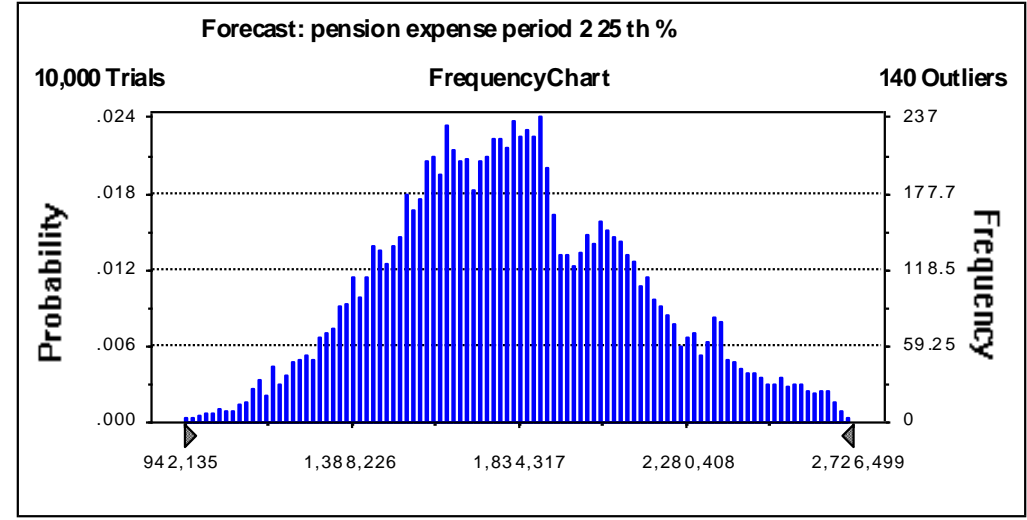


Table 4: Estimation of Pension Expense Using Custom Distribution

\begin{tabular}{|c|c|c|}
\hline Large Company (75\%) & Period 1 & Period 2 \\
\hline Mean & $\$ 15,505473$ & $\$ 21,019,501$ \\
\hline Median & $\$ 13,193,909$ & $\$ 20,593,230$ \\
\hline Standard Deviation & $\$ 4,696,554$ & $\$ 5,644,001$ \\
\hline Minimum & $\$ 4,931,975$ & $\$ 6,368,383$ \\
\hline Maximum & $\$ 35,036,206$ & $\$ 45,231,813$ \\
\hline 95\% Confidence Interval & $\$ 15,413,421-\$ 15,597,525$ & $\$ 20,907,432-\$ 21,131,570$ \\
\hline 75\% Chebyshev Estimate & $\$ 6,112,365-\$ 24,898,581$ & Not Applicable \\
\hline 68\% Emp. Rule Estimate & Not Applicable & $\$ 15,375,500-\$ 26,663,502$ \\
\hline 89\% Chebyshev Estimate & $\$ 1,415,811-\$ 29,595,135$ & Not Applicable \\
\hline 95\% Emp. Rule Estimate & Not Applicable & $\$ 9,731,499-\$ 32,307,503$ \\
\hline Mid-sized Company (50\%) & Period 1 & Period 2 \\
\hline Mean & $\$ 4,991,622$ & $\$ 6,475,745$ \\
\hline Median & $\$ 4,477,666$ & $\$ 6,361,591$ \\
\hline Standard Deviation & $\$ 1,158,892$ & $\$ 1,413,055$ \\
\hline Minimum & $\$ 2,438,860$ & $\$ 2,369,439$ \\
\hline Maximum & $\$ 9,734,144$ & $\$ 13,353,995$ \\
\hline 95\% Confidence Interval & $\$ 4,968,908-\$ 5,014,336$ & $\$ 6,448,049-\$ 6,503,441$ \\
\hline 75\% Chebyshev Estimate & $\$ 2,673,838-\$ 7,309,406$ & Not Applicable \\
\hline $68 \%$ Emp. Rule Estimate & Not Applicable & $\$ 5,062,690-\$ 7,888,800$ \\
\hline 89\% Chebyshev Estimate & $\$ 1,514,946-\$ 8,468,298$ & Not Applicable \\
\hline \multirow[t]{2}{*}{ 95\% Emp. Rule Estimate } & Not Applicable & $\$ 3,649,635-\$ 9,301,855$ \\
\hline & Period 1 & Period 2 \\
\hline Mean & $\$ 1,380,129$ & $\$ 1,835,065$ \\
\hline Median & $\$ 1,231,966$ & $\$ 1,808,178$ \\
\hline Standard Deviation & $\$ 287,806$ & $\$ 354,086$ \\
\hline Minimum & $\$ 754,326$ & $\$ 950,241$ \\
\hline Maximum & $\$ 2,543,908$ & $\$ 3,272,578$ \\
\hline 95\% Confidence Interval & $\$ 1,374,488-\$ 1,385,770$ & $\$ 1,828,125-\$ 1,842,005$ \\
\hline 75\% Chebyshev Estimate & $\$ 804,517-\$ 1,955,741$ & Not Applicable \\
\hline $68 \%$ Emp. Rule Estimate & Not Applicable & $\$ 1,480,979-\$ 2,189,151$ \\
\hline 89\% Chebyshev Estimate & $\$ 516,711-\$ 2,243,547$ & Not Applicable \\
\hline 95\% Emp. Rule Estimate & Not Applicable & $\$ 1,126,893-\$ 2,543,237$ \\
\hline
\end{tabular}

\section{Value Added by Simulation}

In order to demonstrate the predictive value added by representing the various rates as random variables, we used the analytical model to predict pension expense for periods 1 and 2 under the assumption that the values for the three variables - discount rate, expected return on plan assets, and actual return on plan assets - remain static, that is the same as observed in the population. To make our static value prediction, we held the pension rate assumptions constant at the empirical values observed in period 0 . We held the discount rate constant at $7.5 \%$, the expected return on plan assets at $9.5 \%$ and the actual return on plan assets at $8.5 \%$ over the two forecasted periods. Table 5 shows a comparison of pension expense generated with static values with the mean values generated by the two simulation models. As Table 5 demonstrates the model that allows random variation of the three key rates predicts much greater pension expense under both the triangular and the custom distributions. The second panel of the table demonstrates that these significant pension expense increases can have a dramatic effect on predicted net income. The effects are the most striking for the small sized firm where the increase in predicted pension expense under the triangular distribution assumption consumes over 30\% of reported income. Clearly, analysts are better off considering the possibility of the variation of these rates than they would be were they to leave the model at steady state (i.e., a random walk predictive approach). 
Table 5 Static vs. Simulation Comparison

\begin{tabular}{|c|c|c|c|c|c|}
\hline & \multirow[t]{2}{*}{$\begin{array}{c}\text { Static Pension } \\
\text { Prediction }\end{array}$} & \multicolumn{2}{|c|}{$\begin{array}{c}\text { Triangular Distribution Pension } \\
\text { Prediction }\end{array}$} & \multicolumn{2}{|c|}{$\begin{array}{c}\text { Custom Distribution Pension } \\
\text { Prediction }\end{array}$} \\
\hline & & Mean & $\begin{array}{c}\text { Increase Over } \\
\text { Static }\end{array}$ & Mean & $\begin{array}{c}\text { Increase Over } \\
\text { Static }\end{array}$ \\
\hline Large Company--Period 1 & $\$ 6,524,757$ & $\$ 17,506,159$ & $168 \%$ & $\$ 15,505,473$ & $138 \%$ \\
\hline Large Company--Period 2 & $\$ 5,752,820$ & $\$ 27,296,792$ & $374 \%$ & $\$ 21,019,501$ & $265 \%$ \\
\hline Mid-Sized Company--Period 1 & $\$ 2,879,261$ & $\$ 5,404,646$ & $88 \%$ & $\$ 4,991,622$ & $73 \%$ \\
\hline Mid-Sized Company--Period 2 & $\$ 2,742,649$ & $\$ 7,932,338$ & $189 \%$ & $\$ 6,475,745$ & $136 \%$ \\
\hline Small Company--Period 1 & $\$ 873,908$ & $\$ 1,479,656$ & $69 \%$ & $\$ 1,380,129$ & $58 \%$ \\
\hline Small Company_Period 2 & $\$ 934,006$ & $\$ 2,185,707$ & $134 \%$ & $\$ 1,835,065$ & $96 \%$ \\
\hline & & \multicolumn{2}{|c|}{$\begin{array}{c}\text { Triangular Distribution Forecasting } \\
\text { effects }\end{array}$} & \multicolumn{2}{|c|}{$\begin{array}{c}\text { Custom Distribution Forecasting } \\
\text { effects }\end{array}$} \\
\hline & $\begin{array}{c}\text { Pre-tax, Pre- } \\
\text { Pension Income }\end{array}$ & $\begin{array}{c}\text { Increase in } \\
\text { Pension Expense } \\
\text { Using Simulation } \\
\text { Approach } \\
\end{array}$ & $\begin{array}{c}\text { Percent of Income } \\
\text { before Tax and } \\
\text { Pension Expense }\end{array}$ & $\begin{array}{c}\text { Increase in } \\
\text { Pension Expense } \\
\text { Using Simulation } \\
\text { Approach } \\
\end{array}$ & $\begin{array}{c}\text { Percent of Income } \\
\text { before Tax and } \\
\text { Pension Expense }\end{array}$ \\
\hline Large Company--Period 1 & $\$ 277,964,757$ & $\$ 10,981,402$ & $3.95 \%$ & $\$ 8,980,716$ & $3.23 \%$ \\
\hline Large Company--Period 2 & $\$ 277,192,820$ & $\$ 21,543,972$ & $7.77 \%$ & $\$ 15,266,681$ & $5.51 \%$ \\
\hline Mid-Sized Company--Period 1 & $\$ 58,879,261$ & $\$ 2,525,385$ & $4.29 \%$ & $\$ 2,112,361$ & $3.59 \%$ \\
\hline Mid-Sized Company--Period 2 & $\$ 58,742,649$ & $\$ 5,189,689$ & $8.83 \%$ & $\$ 3,733,096$ & $6.36 \%$ \\
\hline Small Company--Period 1 & $\$ 4,093,908$ & $\$ \quad 605,748$ & $14.80 \%$ & $\$ \quad 506,221$ & $12.37 \%$ \\
\hline Small Company-Period 2 & $\$ 4,154,006$ & $\$ 1,251,701$ & $30.13 \%$ & $\$ \quad 901,059$ & $21.69 \%$ \\
\hline
\end{tabular}

\section{Practical Application}

The purpose of this paper is to show how financial analysts can predict pension expense and its associated uncertainties for companies under their review. A simulation approach is a rational one, since it allows the analyst to see the effect on pension expense of various assumptions and/or conjectures about the various rates that drive the pension expense calculation. This, in turn, will indicate to the analyst the risk associated with the pension expense prediction.

Because of the importance and complexity of annual pension expense in the estimate of future earnings, a simulation model acts as a powerful analytical tool for predictive purposes. As our simulation on three hypothetical companies demonstrates, the simulation model can give greater confidence as to the magnitude of this variable that has received so much attention in the popular press. This, in turn, can give the financial analyst greater confidence in the prediction of future earnings and earnings per share.

Our model does not intend to substitute for the intuitive judgment of the analyst. What it is intended to do is make the analyst aware of the amount of uncertainty that that is possible in the estimate of pension expense given the uncertainty of the inputs in that estimate, e.g, the uncertainty in the discount rate, actual rate of return, etc. It might be prudent for the analyst to use differing values of the pension expense in a what-if mode when estimating its effect on profitability.

\section{References}

1. Barth, M., and C. Murphy .1994. "Required financial statement disclosures: Purposes, subject number, and trends". Accounting Horizons (December): 1-22.

2. Brown, K. \& J. Weil. 2001. "Lift's off: Pension costs threaten earnings". The Wall Street Journal (November 13): C1-2. 
3. Bulkeley, W. M. 2002. “IBM's Overfunded pension plan won’t pump up bottom line as much this year as it has in past". The Wall Street Journal (March 15): C2.

4. Carlson, C. 2002. "Mind games: How companies use assets in pension plans to boost profits and trick investors". Bloomberg Personal Finance (November): 29-32.

5. $\quad$ Frederick, J. 2002. "The trouble with earnings". Money (March): 72-76.

6. Newell, G. E., J. G. Kreuze, \& D. Hurtt. 2002 "Corporate pension plans: How consistent are the assumptions in determining pension funding status?" Mid-American Journal of Business (Fall): 23-30.

7. Schultz, E. E., \& A. M. Squeo. 2002. "Pension-plan "crisis' may be false alarm". The Wall Street Journal (November 26): A1, A20.

Notes 